Contemporary Research in Education and English Language Teaching

ISSN: 2641-0230

Vol. 2, No. 2, pp. 36-49

2020

Publisher: Learning Gate

DOI: 10.33094/26410230.2020.22.36.49

(C) 2020 by the authors; licensee Learning Gate

\title{
The Impact of L1 Translation on Adult EFL Learners' Depth of Vocabulary Knowledge
}

\author{
Kamel Boustani \\ Faculty of Letters, Arts and Humanities, Manouba, Tunisia. \\ Email:kamel.boustani@flm.u-manouba.tn
}

Received: 5 October 2020; Revised: 3 November 2020; Accepted: 23 November 2020; Published: 14 December 2020

Abstract: One of the foremost critical challenges that learners may face while learning a foreign language is developing a reliable lexicon and mastering words. Inadequate vocabulary knowledge may put serious barriers within the process of learning a second / foreign language (L2). Thus, students must equip themselves with different strategies to overcome these difficulties. One amongst these strategies that has been heeded by many experts is the use of the first language (L1) translation in learning the vocabulary of L2. However, the effect of this strategy on English as a foreign language (EFL) learners' vocabulary depth remained under explored. Therefore, the primary purpose of this study is to examine the effect of L1 translation on the depth of vocabulary of EFL learners. To attain this goal, a total of 86 Tunisian students, at the fourth year of Secondary Education level, participated in this project. They were randomly selected and divided into a control group and an experimental group. Two Depth of Vocabulary Knowledge tests were assigned to test the research hypotheses. Data was analyzed using two independent-samples t-tests. The findings of the study showed that the participants within the experimental group, who learnt vocabulary through L1 translation strategies, outperformed their counterparts within the control group, who learnt vocabulary through strategies employing only the target language, in relation to their vocabulary depth.

Keywords: Lexicon, EFL, Translation, Vocabulary knowledge, Depth of vocabulary knowledge, Vocabulary learning strategies.

\section{Introduction}

In recent decades, there has been an enormous development of research literature on foreign language learning strategies, particularly in multilingual contexts. Experts from many different disciplines, such as applied linguistics, psycholinguistics, and cognitive psychology, have drawn attention to cross-linguistic factors and their effect on the process of language learning.

The processes involved in the comprehension and production, in two or more languages, have been extensively studied in terms of lexis, phonetics and grammar. Lexis has been recognized as the essence of language (Lewis, 1993) the core of its learning and use. It is the threshold of language learning and the indispensable prerequisite for learning other skills (Laufer, 1997). Actually, the acquisition of a robust lexicon is an extremely important aspect of L2 learning (L2 refers to both second and foreign languages) since learners cannot understand others or communicate their own feelings and thoughts without the appropriate words. Vocabulary is described by Lessard-Clouston (2013) as a language component that includes individual objects, phrases, or chunks of several words that convey specific meanings.

Therefore, basic communicative competence is largely concerned with the strategies that the learners use to solicit the vocabulary they need to get the meanings across. However, knowing a word is a complicated matter and it involves many aspects and dimensions. For instance, lexical knowledge, as 
per (Nation, 2001) involves knowing the word form, its meaning, and its use (e.g. denotative and connotative meanings, spelling, pronunciation, grammar, collocation, and register). Anderson and Freebody (1981) classified the minor dimension of word knowledge by comparing between the breadth and depth of word knowledge. While breadth involves the amount of words learners have acquired, the depth of word knowledge implies how well they understand and use the various aspects of words (Anderson \& Freebody, 1981). For this to take place learners should take actions to help themselves develop their vocabulary knowledge (Cameron, 2001) by using various vocabulary learning strategies. Translation from / to the mother language (L1) is one of these strategies used by EFL learners. However, this strategy has caused conflicts among researchers and experts and evoked clashing attitudes towards its use in the foreign/second language learning process. The arguments against the use of translation in EFL settings were based on the biased view of translation (Vermes, 2010) that was induced in the past by the poor reputation of the Grammar-Translation Method. Cook (2010) calls this an 'insidious association' that has profoundly embedded itself in the collective consciousness of the language-teaching field. Translation, as a teaching / learning strategy, has been disfavored and even ignored in foreign language classrooms.

Recently, this negative attitude towards the use of $\mathrm{L}_{1}$ and translation, in the process of learning foreign languages has gradually lessened. Cook (2010) stated that the first decade of the $21^{\text {st }}$ century witnessed an increased interest in the use of the learners' L1 during the process of L2 learning.

The major goal of the current study is to examine the effect of using L1 translations to learn L2 vocabulary on EFL learners' depth of vocabulary knowledge. To attain this aim, two key questions are addressed:

1. Is there any significant difference between the control group and the experimental group in terms of vocabulary depth in the pre-experiment test?

(Null hypothesis: There is no significant difference between the control group and the experimental group in terms of vocabulary depth in the pre-experiment test.)

2. Does the use of L1 translation have a more significant effect on learners' vocabulary depth than other strategies employing only the L2 when learning vocabulary?

(Null hypothesis: The use of L1 translation strategies does not have a more significant effect on learners' vocabulary depth than other strategies employing only the L2 in vocabulary learning).

\section{Literature Review}

\subsection{Vocabulary Learning Strategies (VLS)}

Studies on general language learning strategies (LLS) provide insight into the particular field of vocabulary learning strategies (VLS). Therefore, VLS are usually seen as a subcategory or a division of LLS, in second or foreign language acquisition (Abadi \& Baradaran, 2013; Nation, 2001) and their rationale derives from that of LLS. Cameron (2001) for example, commonly viewed VLS as measures undertaken by learners to help themselves understand and remember vocabulary. However, Gu (2003) defined them according to their purpose and considered them as direct and indirect learning processes that learners deliberately employ to remember lexical items and use them appropriately in a wide variety of language contexts. Catalan (2003) also, proposed a more concrete definition by stating that they represent the mechanisms used to learn vocabulary as well as the steps or actions taken by students in order to find the meanings of unknown words, retain them in long-term memory, recall them at will, and use them in oral or written modes.

So, it can be said that VLS are actions, techniques, processes, and methods that language learners use to acquire vocabulary (Asgari \& Bin, 2011; Schmitt, 2000). Researchers tried to classify VLS using different taxonomies. For example, Lawson and Hogben (1996) classified the VLS into repetition strategies, word feature analysis strategies, simple elaboration strategies, and complex elaboration strategies. Repetition strategies usually involve reading related words, simple and cumulative rehearsals, writing words and meanings, and testing. Word feature analysis strategies consist in spelling, word classification, and suffixes. Simple elaboration strategies typically consist of translation of sentences, 
simple use of context, similarity of appearance and a sound link. The last category was complex elaboration strategies. These strategies are the complex use of context, paraphrasing, and mnemonic (Lawson \& Hogben, 1996).

According to Schmitt (1997) VLS could be categorized into two different groups: discovery strategies and consolidation strategies. Those strategies used by students to learn the meanings of new words are called discovery strategies, whereas those used to retain and consolidate the meanings of new words are called consolidation strategies. However, discovery strategies comprise determination strategies and social strategies. Translation is included in the category of social strategies which includes asking teachers and classmates for direct translations, synonyms, and paraphrases (Schmitt, 1997). Wenden and Rubin (1987) also classified the VLS under two major kinds of strategies: cognitive learning strategies and metacognitive learning strategies. The cognitive learning strategies incorporate the processes or operations used in language learning as in problem-solving tasks that require direct analysis, translation, or synthesis of learning materials. Nevertheless, metacognitive learning strategies refer to the awareness the learners may develop of these cognitive processes like planning, monitoring, and evaluating (Wenden \& Rubin, 1987).

In sum, during the process of vocabulary learning, language learners use multiple different strategies simultaneously. These strategies can support language learning and enhance learners' selfregulation, self-esteem, and autonomy. Translation from/to $\mathrm{L}_{1}$ is considered as an intentional cognitive strategy used by students to learn new English words and cope with the difficulties of comprehension and communication.

\subsection{Translation as a Learning Strategy and a Pedagogical Tool}

Klaudy (2003) distinguished between two different categories of translation: real translation and pedagogical translation. Real translation is the category of translation intended to boost translation skills, whereas pedagogical translation is an instrumental kind of translation that serves as an instrument to enhance the learner's foreign language skills. Similarly, Gile (1995) made a significant distinction between school translation and professional translation. School translation focuses on the language, while professional translation focuses on the content of language. Indeed, the teaching of translation for professional reasons is often substantively different from the use of translation in academic contexts, and particularly in foreign language learning (Vermes, 2010).

In this study, the use of the term 'translation' does not refer to translation as a real or professional activity, rather it refers to a pedagogical tool used by foreign language learners to facilitate the processes of learning and communication by decoding and converting the information received in one language (L1) into another language (L2), and vice versa (Al-Musawi, 2014). The fundamental role of translation is to understand and convey the correct meaning of a word linguistically, semantically, and pragmatically. Foreign language learners actually resort to translation to deal with the impediments they could face when learning the new language. The development of bilingual or multilingual lexicons could be well achieved through establishing translation links between lexical items in L1 and their equivalents in L2. Oxford (1990) identified translation as transforming and converting the target language (TL) meanings into L1 at various levels, from words to texts, or converting L1 into TL using one language as the basis for understanding or producing another.

Masrai and Milton (2015) found that the acquisition of essential vocabulary is developed by tracing L2 terms from original L1 meanings and they divided the L2 acquired words into two groups: those with direct translation equivalents and those with non-direct translation equivalents. The meaning of equivalence in this context is semantic similarity between lexical items in different languages.

\subsection{Vocabulary Knowledge}

The term 'vocabulary knowledge' seems to be ambiguous since many learners think that knowing vocabulary simply knows the forms of words. Many researchers in the field of foreign vocabulary acquisition have mentioned that several types of sub-knowledge are necessary to 'know a word'.

Contemporary Research in Education and English Language Teaching

ISSN: 2641-0230

Vol. 2, No. 2, pp. 36-49, 2020

DOI: $10.33094 / 26410230.2020 .22 .36 .49$

(C) 2020 by the authors; licensee Learning Gate 
Examples include (Cronbach, 1942) who found that defining the knowledge of a word is confusing and he made the distinction between five components of lexical knowledge: generalization, application, breadth of meaning, precision of meaning, and availability. With generalization, he refers to the ability of defining a word and with application he refers to the ability to use the word. The breadth of meaning is the knowledge of different senses of a word, the precision of meaning is the use the word in different situations, and availability refers to the ability to use the word productively (Cronbach, 1942).

More recently, Nation (as cited in Bogaards (2000)) has suggested four dimensions of lexical knowledge: the form (written or spoken), the position (grammar and collocations), the function (frequency and appropriateness), and the meaning (conceptual and associative). Also, Laufer (1997) tried to write a list of the aspects of vocabulary knowledge after reviewing several research projects dealing with the definition of words. This list included word form (e.g. Pronunciation and spelling), word structure (e.g. roots, derivations, and inflections), its syntactic patterns, its multiple meanings (e.g. metaphorical, affective, and pragmatic meanings), and its relations with other words (e.g. synonyms, antonyms, hyponyms, and collocations).

Milton (2009) considered that being able to use words effectively includes many types of knowledge. The most critical among these kinds of knowledge are the receptive/productive knowledge and breadth/depth of words. Receptive knowledge refers to word recognition while listening or reading, whereas productive knowledge refers to the appropriate use of words during speaking or writing. The second type of knowledge is the breadth and depth of words. The Breadth dimension of vocabulary knowledge refers to the number of lexical items a learner knows, whereas the depth dimension of vocabulary knowledge refers to what the learner knows about these lexical items (Milton, 2009).

\subsection{Depth of Vocabulary Knowledge}

Like Milton (2009) categorization of vocabulary knowledge, Anderson and Freebody (1981) reduced the dimensions of word knowledge into two broad categories: the breadth of vocabulary knowledge and the depth of vocabulary knowledge. The breadth or size of vocabulary knowledge refers to number of words a learner knows, and the depth of vocabulary knowledge refers to what the learner knows about these words (Anderson \& Freebody, 1981; Milton. \& Fitzpatrick, 2014). According to Ordonez, Carlo, Snow, and McLaughlin (2002) the depth of vocabulary is the richness of the representation of the words known. They consider that this dimension of vocabulary knowledge has several components : (1) the quality of the representation of the phonology and orthography, (2) the knowledge of the syntactic structures and word class(es), (3) the knowledge of the word's morphological structure and its susceptibility to derivational processes, (4) the richness of the semantic representation of the word, including information about its core meaning, its connotations, its potential for polysemy; and (5) the knowledge of the pragmatic rules for using the word, including its sociolinguistic register, its degree of formality, and its appropriateness to various contexts. Analogously, Meara (1996) claimed that the term depth of vocabulary describes to the quality of lexical knowledge and how well the learner knows a word. Ellis (2008) considered the depth of vocabulary as an important component of vocabulary acquisition and defined it as the extent to which the learners have acquired various properties of the word (e.g. its syntactical function and collocations). Along the same line, Henriksen (1996) defined vocabulary depth as the degree of knowledge of words' syntagmatic and paradigmatic relations with other words. Nation (2001) found that knowing a word involves knowing not only its form, including spoken and written forms, but also its meaning (including form and meaning, concept and reference, and associations) and use (including grammatical functions, collocations, and constraints on use). Hence, the depth of vocabulary knowledge can be defined as learners 'knowledge of the words' meanings at the lexical, syntactical, and contextual levels.

\subsection{The Effect of L1 Translation on Vocabulary Knowledge}

Several studies have demonstrated that $\mathrm{L}_{1}$ is active during $\mathrm{L}_{2}$ lexical processing in both beginning and more advanced learners (e.g. (Hall, 2002; Sunderman \& Kroll, 2006)) and that learners need support 
to work out the meanings of new words. These studies demonstrated that providing the learners with a translation into their L1 could really aid in the process of learning the vocabulary of the target language (Cameron, 2001).

Accordingly, Khan (2016) attempted to explore the effect of L1 use on foreign language vocabulary learning among Saudi EFL learners. Findings showed evidence that learning English as foreign language is significantly promoted by the use of translation. Boustani (2019) sought to investigate the association between the learning strategy of translation equivalence and EFL learners' speaking anxiety. He concluded that using translation, as a pedagogical tool to learn L2 vocabulary, is effective and efficient since it helps learners develop their vocabulary skills and it facilitates the learning process in a manner that contributes positively to reducing the degree of speaking anxiety they may experience in class.

Likewise, Joyce (2015) conducted research on 48 Japanese learners of English to investigate the effect of using L1 translations versus L2 definitions on L2 vocabulary knowledge. The findings indicated that the learners' recognition of the L2 lexical items was drastically increased when they matched the English words to their L1 translations, rather than to their L2 definitions.

Nonetheless, in the communicative approach, there is a common assumption that using translation makes no contribution to the foreign language development (Marqués-Aguado \& Solís-Becerra, 2013). Alroe and Reinders (2015) also explored the results of previous studies through a replication study, finding that EFL learners could learn new vocabulary faster by translating them rather than learning them in context. The results of this study showed that the group who learned the words through translation did not do better than the two other groups who contextually learned them (Alroe \& Reinders, 2015).

\subsection{The Effect of L1 Translation on L2 Vocabulary Depth}

EFL vocabulary learners may face difficulties, when learning L2 vocabulary, with the number of words to be acquired, and with the development of in-depth understanding of such lexical representations. Perfetti and Hart (2002) stated that learners can develop their vocabulary depth by studying associations between words. Proctor, August, Carlo, and Snow (2005) conducted research to show that stronger second-language performance was correlated positively with good native-language vocabulary abilities. Their findings proved that L1 vocabulary skills of the participants were highly associated with the target language vocabulary skills. Also, Wolter (2001) in his model of the depth of individual word knowledge, compared the L1 and L2 mental lexicons and showed that the depth of word knowledge is a key for determining the degree of integration for the individual words that make up the structure of both the $\mathrm{L} 1$ and the $\mathrm{L} 2$ mental lexicons.

Zheng (2011) investigated the L1 impact on L2 vocabulary depth of 87 postsecondary Chinese EFL learners. Learners' L1 was reported to induce an asymmetrical effect on the meaning senses and collocations and the participants tended to be more sensitive to the L1 congruence effect on the collocation aspect (Zheng, 2011).

Yet, other studies did not find significant relationships between L1 and L2 vocabulary knowledge. Bangngu (2017) for instance, conducted a study on Indonesian university students to explore the impact of different vocabulary learning strategies on the depth of their vocabulary knowledge. Results showed that only determination, social and metacognitive strategies had significant impact on learners' vocabulary depth.

\section{Method}

This research is a quantitative experimental study that attempts to investigate the effect of L1 translation, as a strategy of learning foreign language vocabulary, on Tunisian adult learners' vocabulary depth. 


\subsection{Setting and Participants}

This project took place in different secondary schools, in Tunisia. The $4^{\text {th }}$ year of Secondary Education students (At the end of the $4^{\text {th }}$ year of Secondary Education, students take the National Baccalaureate Exam) are the target population. A total of 86 participants, aged between 18 and 22, were randomly selected to reach a good level of representation accuracy and give equal chances to all the members of the population to be selected. They were 37 males (43\%) and 49 females (57\%).

They were all Tunisians with Arabic as their first language. They have attended English classes for eight years to the time of data gathering (from the 6th grade of Basic Education to the 4th year of Secondary Education).

The research works have been carried out in compliance with the principles of research and publication ethics, and before participating in the study, all informants gave their informed consent for inclusion.

\subsection{Research Instruments}

To answer the research questions of this study, two versions of the Depth of Vocabulary Knowledge (DVK) test were used: a pre-experiment test and a post-experiment one. This test is like the one used by Teng (2014) in a study about the depth of vocabulary knowledge of Chinese EFL learners. Each version of the tests includes two sections. The first section is based on the developmental approach which reflects the incremental nature of the vocabulary acquisition (Read, 2000) and it is represented by the Vocabulary Knowledge Scale (VKS) designed by Wesche and Paribakht (1996). This section is a fivescale inventory in which learners were asked to respond to 50 words with:

1. I do not remember having seen this word before.

2. I have seen this word before, and I am only familiar with the form.

3. I have seen this word before, and I think it means____ (synonym or translation).

4. I know this word. It means__ (synonym or translation).

5. I can use this word in a sentence

In its current form, this section is meant to measure the knowledge of only one meaning and its related use. The following table explains the different aspects to be measured by this adapted version of the VKS:

Table-1.

Aspects measured in the VKS.

\begin{tabular}{|c|c|c|}
\hline Aspects & Scales & Self-report \\
\hline \multirow{2}{*}{ Form } & 1 & I do not remember having seen this word before. \\
\hline & 2 & I have seen this word before, and I am only familiar with the form. \\
\hline \multirow[t]{2}{*}{ Meaning } & 3 & I have seen this word before, and I think it means.................. \\
\hline & 4 & I know this word. It means. $\ldots \ldots \ldots \ldots \ldots \ldots \ldots \ldots \ldots \ldots \ldots \ldots \ldots \ldots$ \\
\hline Usage & 5 & 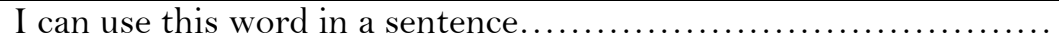 \\
\hline
\end{tabular}

The minimum score of this section (VKS) is $50(1 * 50)$ and the maximum score is $250(5 * 50)$, with one as the minimum scale, 5 as the maximum scale and 50 as the number of items used in this section of the test.

The second section is the Word Associates Test (WAT). It was developed by Read (1998) and it is based on the dimensional approach which assumes that vocabulary depth encompasses various aspects of word knowledge (Read, 2000). It consists of 50 items testing whether the participant could identify the relationships between the stimulus word and eight options. The following is an example:

Stimulus word: CORRECT

\begin{tabular}{|c|c|c|c|c|c|c|c|}
\hline easy & free & right & True & answer & dream & enemy & \\
\hline
\end{tabular}


All the words on the left are adjectives, and all those on the right are nouns. Participants have to identify the possible relationships between the stimulus word and the words on the left and on the right. The minimum score of this section is 0 and the maximum score is 200.

All the lexical items in the two sections of the test are selected from the 3000 and 5000 Oxford lists that can be accessed from the following link:

https://www.oxfordlearnersdictionaries.com/wordlists/oxford3000-5000

They were crosschecked with the participants' textbooks and the official programs to ensure that they have encountered them. They were selected from different parts of speech and from different frequency levels (high and low frequencies) to check the learners' vocabulary knowledge on both levels of word frequency.

\subsection{Reliability of the Research Instruments}

The Cronbach's alpha coefficient was used to measure the reliability of both research instruments. The two tests have a very good internal consistency. The following table (Table 2) summarizes the reliability outputs of the research instruments as generated by the SPSS software:

Table-2.

Reliability of research instruments.

\begin{tabular}{l|c|c}
\hline & DVK Pre-test & DVK Post-test \\
\hline Cronbach's Alpha & .862 & .894 \\
\hline Cronbach's Alpha Based on Standardized Items & .864 & .900 \\
\hline Number of Items & $100(50+50)$ & $100(50+50)$ \\
\hline Removed items & 0 & 0 \\
\hline Valid cases & 86 & 86 \\
\hline Excluded cases & 0 & 0 \\
\hline
\end{tabular}

\subsection{Procedures}

The selected sample was randomly divided into two groups: a control group and an experimental group. In this experiment, data from the control group is compared to data from the experimental group at two stages: pre-experiment stage and post-experiment stage. These two groups are identical in every respect except one: The fundamental distinction between the control group and the experimental group is that the independent variable is modified for the experimental group but is kept constant in the control group. In other words, the control group, as it is the norm in Tunisia (as stated in the official curricula), learnt vocabulary only through strategies employing the TL (e.g., defining, giving synonyms and antonyms, contextualization, visuals, etc.). The use of $\mathrm{L} 1$, in this group, is strictly banned. However, in the experimental group, foreign language vocabulary learning is mainly based on translation strategies (e.g., using bilingual dictionaries, asking peers and teachers about translation equivalents, using bilingual word lists, using bilingual cards, etc.).

The two groups had gone through three main phases during this experiment:

1. Pre-experiment phase: the two groups took the same pre-experiment version of the DVK test to check their homogeneity and their level of proficiency.

2. While-experiment phase: the two groups received a 6-week training in which they use different strategies of learning vocabulary (as it is explained above).

3. Post-experiment phase: the two groups took the same post-experiment version of the DVK test in order to compare their results and to investigate whether there was a significant impact of translation strategies on the participants' vocabulary depth or not. 


\subsection{Data Analysis Methods}

To analyse data, SPSS 26 was used. Two independent-samples t-tests were performed to answer the two research questions of this project. Comparing means, interpreting confidence intervals for the difference of means and effect sizes were the main statistical techniques employed for data analysis.

\section{Findings}

\subsection{Analysing the Results of the Pre-Experiment Test}

To answer the first research question, it was hypothesized that there is no significant difference between the control group and the experimental group in terms of vocabulary depth in the preexperiment test. First, the independent samples t-test assumptions were checked. There were no significant outliers in the data as it was assessed by the inspection of boxplots. Scores were verified using the Shapiro-Wilks test, and they were found to approximate a normal distribution.

Second, the Group Statistics table (Table 3) was analysed. It shows the number of participants in each group, the mean scores, the standard deviation, and the standard error means:

Table-3.

Group Statistics.

\begin{tabular}{c|c|c|c|c|c}
\hline & Groups & N & Mean & Std. Deviation & Std. Error Mean \\
\hline \multirow{2}{*}{$\begin{array}{c}\text { DVK (Pre- } \\
\text { test) }\end{array}$} & Control Group & 43 & 179.56 & 36.84 & 5.62 \\
\cline { 2 - 6 } & Experimental Group & 43 & 175.30 & 42.45 & 6.47 \\
\hline
\end{tabular}

The control group obtained a mean score of $M_{l}=179.56, S D=36.84$ and the experimental group obtained a mean score of $M_{2}=175.30, S D=42.45$. The mean difference is $M_{D i f f}\left(M_{1}-M_{2}\right)=4.26$, which can be considered as a very small difference in a test scored out of 450 (First section: VKS / 250; second section: WAT / 200).

The following error bar graph (Figure 1) represents the $95 \%$ confidence intervals for the means of the two groups. The small circle in the middle of each error bar is the mean score for each group:

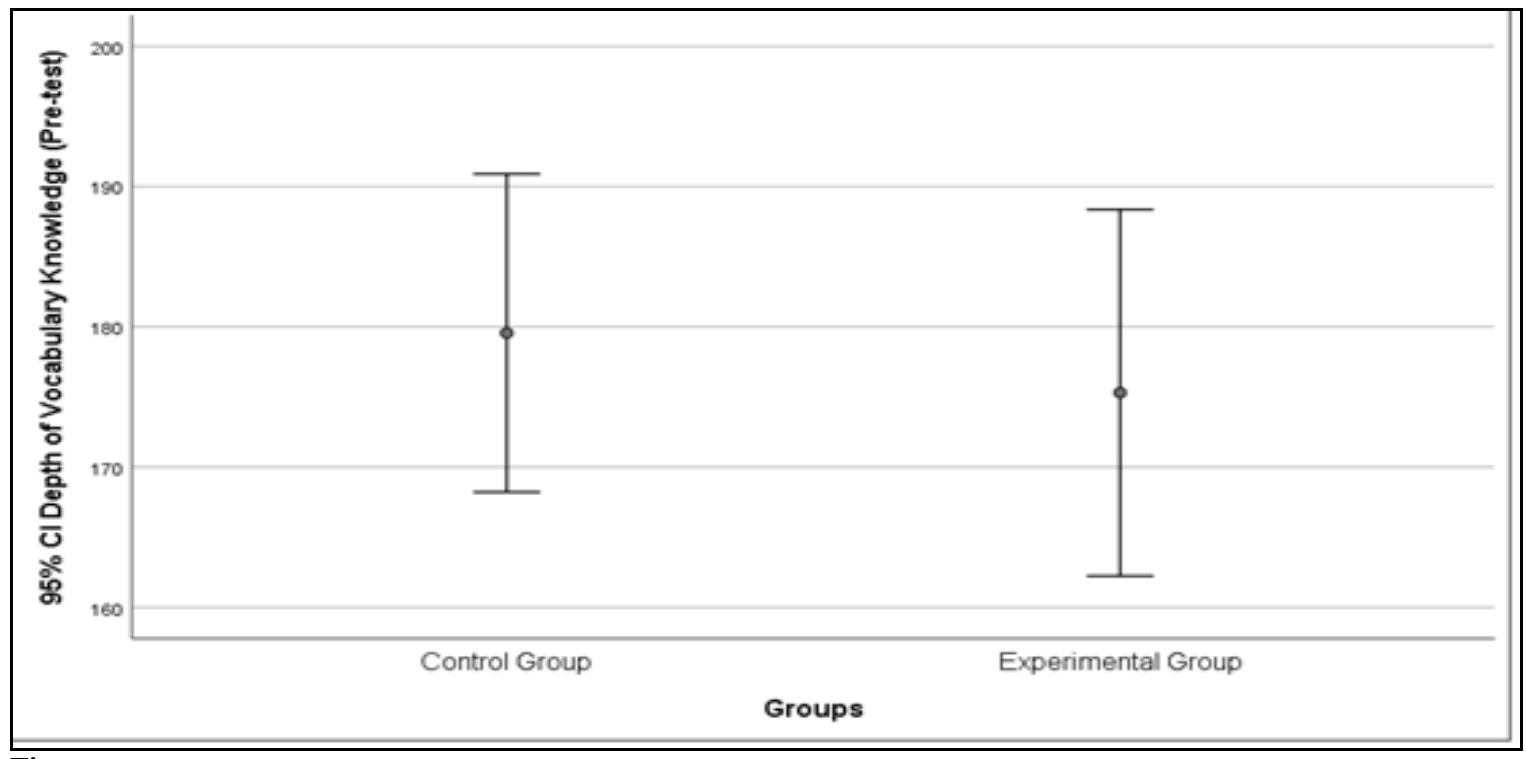

Figure-1.

The $95 \%$ CI for the means of the control and experimental groups (Pre-test). 
As shown in this figure, there is an overlap between the two $95 \%$ confidence intervals for the means of the two groups which implies that there is no significant difference between the scores of the control group and the experimental group in the pre-experiment DVK test.

The next step is to analyze the independent samples t-test. The Levene's test for equality of variances Table 4 is necessary to check the assumption of homogeneity and decide which assumption to use to interpret the independent t-test results; if $p$ is not significant $(p \geq .05)$, the assumption is not violated and the row of the Equal Variances Assumed should be used. The assumption of equal variances is violated if $p$ is statistically significant $(p<.05)$, the variances are substantially distinct, and (Pallant, $2011)$.

Table-4.

Levene's Test for Equality of Variances.

\begin{tabular}{l|l|c|c}
\hline & & $\mathbf{F}$ & Sig. \\
\hline \multirow{2}{*}{ DVK (Pre-test) } & Equal variances assumed & 1.75 & .19 \\
\cline { 2 - 4 } & Equal variances not assumed & & \\
\hline
\end{tabular}

In this case, The Levene's Test proved no violation of homogeneity of variances $(p>.05)$. So, the first row of Equal Variances Assumed in the independent-samples t-test (Table 5) is to be used:

Table-5.

The independent samples t-test.

\begin{tabular}{c|c|c|c|c|c|c|c|c}
\hline \multicolumn{4}{c|}{} & \multicolumn{2}{c|}{$\begin{array}{c}\text { t-test for } \\
\text { Equality of } \\
\text { Means }\end{array}$} & \multicolumn{2}{c}{$\begin{array}{c}\text { 95 \% CI for the } \\
\text { difference of } \\
\text { means }\end{array}$} \\
\hline \multirow{2}{*}{} & $\mathrm{t}$ & $\mathrm{df}$ & $\mathrm{sig}$ & $\begin{array}{c}\text { Mean } \\
\text { diff. }\end{array}$ & $\begin{array}{c}\text { STD } \\
\text { Error } \\
\text { Diff. }\end{array}$ & Upper & Lower \\
\hline $\begin{array}{c}\text { DVK } \\
\text { (Pre- } \\
\text { test) }\end{array}$ & $\begin{array}{c}\text { Equal Variances } \\
\text { Assumed }\end{array}$ & .50 & 84 & .62 & 4.26 & 8.57 & -12.79 & 21.30 \\
\cline { 2 - 10 } & $\begin{array}{c}\text { Equal Variances } \\
\text { Not Assumed }\end{array}$ & .50 & 82.37 & .62 & 4.26 & 8.57 & -12.79 & 21.31 \\
\hline
\end{tabular}

The results of the independent-samples t-test showed an insignificant difference between the mean scores of the two groups with $t(84)=.50$ and $p>.05$. Also, the $95 \%$ confidence interval for the difference of means CI [-12.79,21.30] captures the value of zero which means that the difference could be equal to zero.

The effect size for the independent-samples t-test is a statistic that provides an indication of the magnitude of the differences between the two groups. SPSS software does not provide it. So, Pallant (2011) suggested using the Partial Eta Squared effect size that can be calculated using the following formula:

Partial Eta squared $\eta p^{2}=t^{2} / t^{2}+\left(N_{1}+N_{2}-2\right)$; with $t$ referring to the t-statistic value in the t-test, $N_{t}$ is the number of participants in the control group and $N_{2}$ is the number of participants in the experimental group. This formula gives an effect size of the difference between the two groups $\eta p^{2}=$ 0.003 which is considered by Cohen (1977) as a very small effect size.

To sum up, the null hypothesis assumed that there is no significant difference between the mean scores of the two groups $\left(\mathrm{H}_{0}: M_{i}=M_{2}\right)$. The participants in the two groups sat for a DVK test, before starting the experiment of the study, in order to check their homogeneity and their level of proficiency. An independent samples t-test was performed to determine whether there is a statistically significant difference between the means of the control group $\left(M_{i}=179.56, S D=36.84\right)$ and the experimental group $\left(M_{2}=175.30, S D=42.45\right)$. The group statistics (Table 3) revealed that there was no significant 
difference between the mean scores of the two groups $\left(M_{1}-M_{2}=4.26\right)$. The lower and upper bounds of the $95 \% \mathrm{CI}[-12.79,21.30]$ included the zero value which means that the null hypothesis claim of zero difference between the means of the control group and the experimental groups in the DVK test was true. The effect size of the difference between the means of the two groups was very weak $\eta p^{2}=0.003$. Therefore, the null hypothesis cannot be rejected since the two groups were homogeneous and there was no statistically significant difference between their mean scores in the pre-experiment DVK test.

\subsection{Analysing the Results of the Post-Experiment Test}

In the post-experiment DVK test, the control group obtained a mean score of $M_{i}=201.00, S D=$ 44.51, and the experimental group obtained a mean score of $M_{2}=239.95, S D=52.76$. The following table shows the group Statistics illustrating the mean scores:

Table-6.

Group Statistics

\begin{tabular}{l|l|l|l|l|l}
\hline & Groups & N & Mean & Std. Deviation & Std. Error Mean \\
\hline DVK (Pre-test) & Control Group & 43 & 201.00 & 44.51 & 6.79 \\
\cline { 2 - 5 } & $\begin{array}{l}\text { Experimental } \\
\text { Group }\end{array}$ & 43 & 239.95 & 52.76 & 8.05 \\
\hline
\end{tabular}

Table 6 shows that the mean score of the experimental group $\left(M_{2}=239.95, S D=52.76\right)$ was higher than the mean score of the control group $\left(M_{l}=201.00, S D=44.51\right)$ with a mean difference of $M_{d i t f}=M_{2-}$ $M_{l}=38.95$.

The following error bar graph shows this difference of means with the two $95 \%$ confidence intervals:

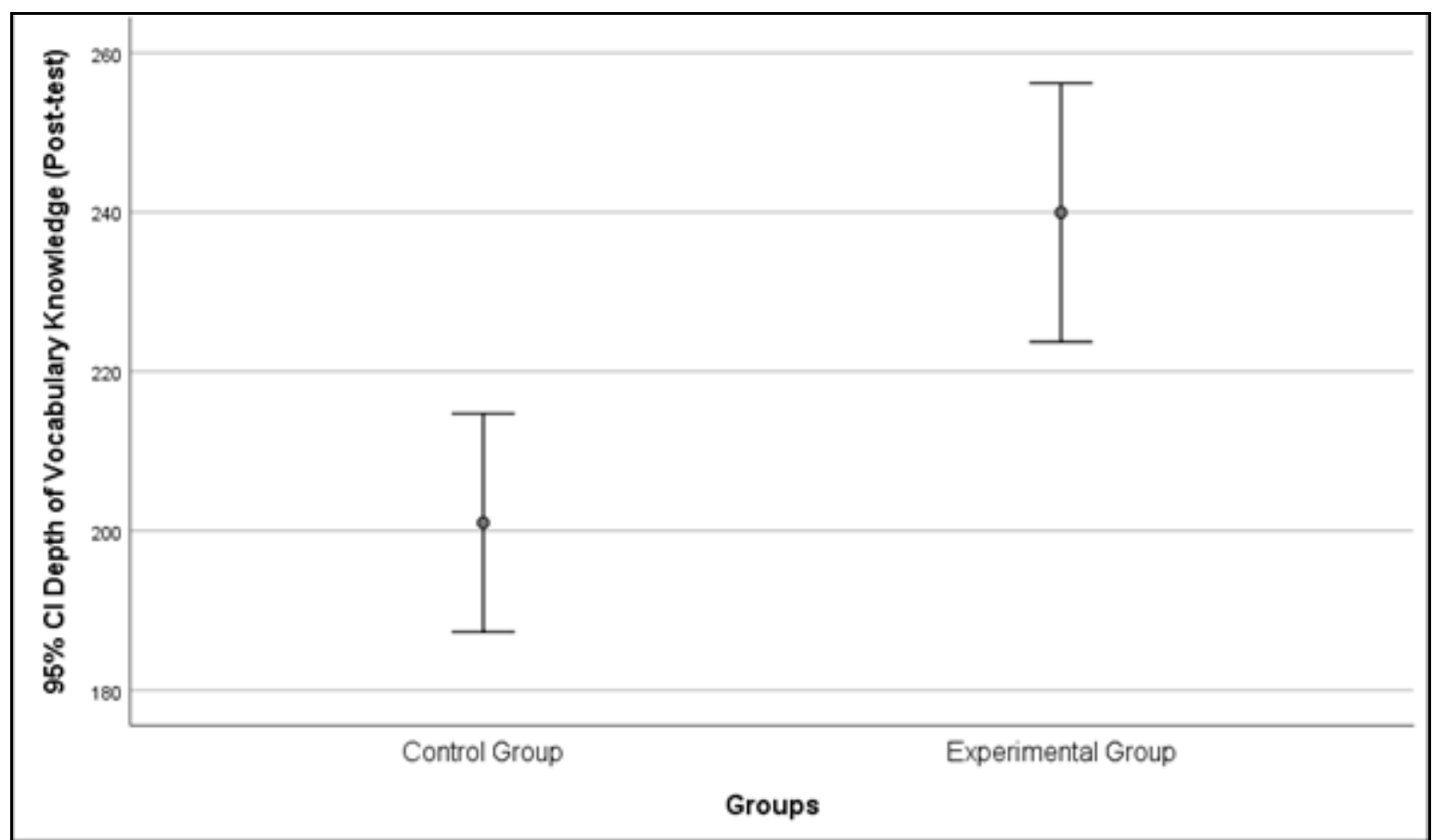

Figure-2

The $95 \%$ CI for the means of the control and experimental groups (Post-test). 
This figure (Figure 2) shows that the two $95 \%$ confidence intervals are non-overlapping which reveals a significant difference between the two groups.

To interpret results of the independent samples t-test, the Levene's test was checked first to decide which row of the t-test would be used. Table 7 shows that the Levene's test is not significant with $F=$ 2.22, $p=.14$. Therefore, the row of Equal Variances Assumed in the independent-samples t-test table (Table 8 ) should be used:

Table-7.

Levene's Test for Equality of Variances.

\begin{tabular}{l|l|c|c}
\hline & & F & Sig. \\
\hline DVK (Pre-test) & Equal variances assumed & 2.22 & .14 \\
\cline { 2 - 4 } & $\begin{array}{l}\text { Equal variances not } \\
\text { assumed }\end{array}$ & & \\
\hline
\end{tabular}

The results of the independent samples t-test (Table 8) showed a large difference in means between the control group and the experimental group with $t(84)=-3.70$ and $p<.001, M_{\text {Diff }}=M_{1}-M_{2}=-38.95$. The $95 \%$ confidence interval for the difference of means CI [-59.89, -18.02] does not include the zero value which means that the claim of the null hypothesis that the $M_{D_{i f f}}\left(M_{i}-M_{2}\right)=0$ is not true and can, therefore, be rejected.

Table-8.

The independent samples t-test.

\begin{tabular}{|c|c|c|c|c|c|c|c|c|}
\hline & & & & & $\begin{array}{r}\text { t-te } \\
\text { Equa } \\
M\end{array}$ & $\begin{array}{l}\text { for } \\
y \text { of } \\
\text { is }\end{array}$ & $\begin{array}{r}95 \% \\
\text { diffe } \\
n\end{array}$ & $\begin{array}{l}\text { for the } \\
\text { ce of } \\
\text { ns }\end{array}$ \\
\hline & & $\mathrm{t}$ & $\mathrm{df}$ & sig & $\begin{array}{l}\text { Mean } \\
\text { diff. }\end{array}$ & $\begin{array}{l}\text { STD } \\
\text { Error } \\
\text { Diff. }\end{array}$ & Upper & Lower \\
\hline \multirow{2}{*}{$\begin{array}{l}\text { DVK } \\
\text { (Pre- } \\
\text { test) }\end{array}$} & $\begin{array}{c}\text { Equal Variances } \\
\text { Assumed }\end{array}$ & -3.70 & 84 & .00 & -38.95 & 10.53 & -59.89 & -18.02 \\
\hline & $\begin{array}{c}\text { Equal Variances } \\
\text { Not Assumed }\end{array}$ & -3.70 & 81.68 & .00 & -38.95 & 10.53 & -59.90 & -18.01 \\
\hline
\end{tabular}

Also, the Partial Eta Squared used for this test to measure the effect size of the difference between the means of the two groups was calculated using the same formula used for the pre-experiment independent-samples t-test $\left(\eta p^{2}=t^{2} / t^{2}+\left(N_{t}+N_{2}-2\right)\right)$ to give $\eta p^{2}=0.140$. This effect size is considered by Cohen (1977) as a very large effect size.

In sum, after taking the pre-experiment DVK test, the participants in the two groups (control and experimental) went through a 6-week training in which the control group learnt vocabulary using strategies employing only the English language (Definition, synonyms, contextualization, visuals, etc...) and the experimental group learnt vocabulary using L1 translation strategies (Bilingual dictionaries, bilingual word lists, asking teachers and peers about translation equivalents, etc.). Then, they took another DVK test. An independent-samples t-test was used to test the null hypothesis claiming that translation has no greater impact on learners' vocabulary depth than other strategies employing only English in vocabulary learning. Results revealed that the mean score of the experimental group $\left(M_{2}=\right.$ 239.95, $S D=52.76)$ was higher than the mean score of the control group $\left(M_{l}=201.00, S D=44.51\right)$ with a large difference of means $M_{D i f f}\left(M_{t}-M_{2}\right)=-38.95$. The Partial Eta Squared for the difference between the means of the two groups was very large $\eta p^{2}=0.140$ which means that this difference is statistically significant. Therefore, the null hypothesis could be rejected, and we can conclude the L1 
translation has a greater impact on learners' vocabulary depth development than other strategies employing only L2 (English).

\section{Discussion}

All the statistical techniques used, in this study, provided evidence that participants who learnt vocabulary during the 6-week period using L1 translation obtained better scores in the post-experiment DVK test which proves that the use of translation as a learning strategy has a very positive impact on the process of vocabulary learning, in general, and on the depth of vocabulary knowledge, in particular. These findings substantiate Cameron (2001) and Khan (2016) studies in which they showed that L1 translation is a helpful pedagogical tool in learning foreign languages. Moreover, the results of this study correlate favorably with Liu (2008) and Boustani (2019) who demonstrated through their research projects that the mother language was significantly beneficial to the learners in learning and understanding the meanings of new words and expressions of the TL.

Besides, the results of this study are in line with the results of Joyce (2015) which proved that the learners' recognition of the L2 lexical items was considerably higher when they were asked to match the English words to their L1 translations than their L2 definitions. For this reason, Batia Laufer and Girsai (2008) emphasized the crucial need to use translation and contrastive analysis in language learning.

However, the current study significantly differs from Alroe and Reinders (2015) who showed through their research that studying vocabulary contextually is better than studying it through translation. Similar to Alroe and Reinders (2015); Marqués-Aguado and Solís-Becerra (2013) presented different results to this study when they found evidence that translation has little contribution to L2 vocabulary development and that the learners' vocabulary knowledge could be improved through other strategies than translation.

\section{Conclusion}

This study was conducted to explore the impact of Translation on EFL learners' vocabulary depth. Two independent samples t-tests were conducted to test the two research hypotheses. The first independent-samples t-test, used to analyze the pre-experiment Depth of Vocabulary Knowledge scores, showed that the control group and the experimental group, that were randomly selected, were homogeneous and their mean scores were not significantly different. This means that the control group and the experimental group were not different in terms of vocabulary depth, before the experiment. The second independent-samples t-test was used to analyze data collected through the post-experiment Depth of Vocabulary knowledge test. Results showed that the mean scores of the experimental group that learnt vocabulary through translation were higher than the mean scores of the control group that learnt vocabulary through non-translation strategies which used only the target language.

The results of this study suggest that translation should not be banned from the EFL classroom. It should be treated as a pedagogical tool that complements existing approaches to foreign language learning/teaching and helps learners to develop their vocabulary and construct a reliable lexicon. However, this does not imply overusing L1 translation and becoming so dependent on it in a way that teachers and learners cannot function in a second or foreign language classroom without it. Whatever benefits L1 use can bring, learning the target language remains the ultimate goal of a second or foreign language classroom and a balance between the learning strategies is highly recommended.

\section{References}

Abadi, E. A. M., \& Baradaran, A. (2013). The relationship between learner autonomy and vocabulary learning strategies in Iranian EFL learners with different language proficiency level. International Journal of Applied Linguistics and English Literature, 2(3), 176-185.Available at: https://doi.org/10.7575/aiac.ijalel.v.2n.3p.176.

Al-Musawi, N. M. (2014). Strategic use of translation in learning English as a foreign language (EFL) among Bahrain university students. Comprehensive Psychology, 3, 10.03. IT. 13.14.Available at: https://doi.org/10.2466/10.03.it.3.4.

Alroe, M. J., \& Reinders, H. (2015). The role of translation in vocabulary acquisition: A replication study. Eurasian Journal of Applied Linguistics, 1, 39-58.Available at: 10.32601/ejal.460588. 
Anderson, R. C., \& Freebody, P. (1981). Vocabulary knowledge. In J. T. Guthrie (Ed.), Comprehension and teaching: Research reviews (pp. 77-117). New York: International Reading Association.

Asgari, A., \& Bin, M. G. (2011). The type of vocabulary learning strategies used by ESL students in university Putra Malaysia. English Language Teaching, 4(2), 84-90.

Bangngu, E. A. (2017). Effects of EFL students' vocabulary learning strategies on their depth of vocabulary knowledge. SMCC Higher Education Research Journal, 3(1), 1-13.Available at: 10.18868/sher3j.03.00117.02.

Bogaards, P. (2000). Testing L2 vocabulary knowledge at a high level: The case of the Euralex French tests. Applied Linguistics, 21(4), 490-5 16.Available at: https://doi.org/10.1093/applin/21.4.490.

Boustani, K. (2019). The correlation between translation equivalence, as a vocabulary learning strategy, and Tunisian EFL learners' speaking anxiety. Languages, 4(1), 1-24.Available at: https://doi.org/10.3390/languages4010019.

Cameron, L. (2001). Teaching languages to young learners. Cambridge: Cambridge University Press.

Catalan, R. M. J. (2003). Sex differences in L2 vocabulary learning strategies. International Journal of Applied Linguistics, 13(1), 54-77.Available at: https://doi.org/10.1111/1473-4192.00037.

Cohen, J. (1977). Statistical power analysis for the behavioral sciences (Revised ed.). USA: Academic Press.

Cook, G. (2010). Translation in language teaching. Oxford: Oxford University Press.

Cronbach, L. J. (1942). An analysis of techniques for diagnostic vocabulary testing. The Journal of Educational Rsearch, 36(3), 206-217.Available at: https://doi.org/10.1080/00220671.1942.10881160.

Ellis, R. (2008). The study of second language acquisition (2nd ed.). Oxford: Oxford University Press.

Gile, D. (1995). Basic concepts and models for interpreter and translator training. Amsterdam and Philadelphia: John Benjamins.

Gu, P. Y. (2003). Vocabulary learning in a second language: Person, task, context and strategies. TESL-EJ, 7(2), 1-25.

Hall, C. J. (2002). The automatic cognate form assumption: Evidence for the parasitic model of vocabulary development. IRALInternational Review of Applied Linguistics in Language Teaching, 40(2), 69-87.Available at: https://doi.org/10.1515/iral.2002.008.

Henriksen, B. (1996). Somatization, Retention and accessibility: Key concepts in vocabulary learning. Paper presented at the AILA Congress, Jyvaskyla, Finland.

Joyce, P. (2015). L2 vocabulary learning and testing: The use of L1 translation versus L2 definition. The Language Learning Journal, 1-12.Available at: 10.1080/09571736.2015.1028088.

Khan, M. S. (2016). The impact of native language use on second language learning by Saudi EFL students. English Language Teaching, 9(5), 134-140.Available at: https://doi.org/10.5539/elt.v9n5p134.

Klaudy, K. (2003). Languages in translation. Budapest: Scholastica.

Laufer, B. (1997). The lexical plight in second language reading: words you don't know, words you think you know and words you can't guess. In J. Coady, \& T. Huckin (Eds.), Second language vocabulary acquisition: A rationale for pedagogy (pp. 20-34). Cambridge: Cambridge University Press.

Laufer, B., \& Girsai, N. (2008). Form-focused instruction in second language vocabulary learning: A case for contrastive analysis and translation. Applied Linguistics, 29(4), 694-716.Available at: https://doi.org/10.1093/applin/amno 18.

Lawson, M. J., \& Hogben, D. (1996). The vocabulary-learning strategies of foreign-language students. Language Learning, 46(1), 101-135.

Lessard-Clouston, M. (2013). Teaching vocabulary. Alexandria: TESOL International Association.

Lewis, M. (1993). The lexical approach: The state of ELT and a way forward. Hove: Language Teaching Public.

Liu, J. (2008). L1 use in L2 vocabulary learning: Facilitator or barrier. International Education Studies, 1(2), 65-69.Available at: https://doi.org/10.5539/ies.v1n2p65.

Marqués-Aguado, T., \& Solís-Becerra, J. (2013). An overview of translation in language teaching methods: Implications for EFL in secondary education in the region of Murcia. Journal of Linguistics and Applied Languages, 8, 38-48.Available at: $10.4995 /$ rlyla.2013.1161.

Masrai, A., \& Milton, J. (2015). An investigation of the relationship between L1 lexical translation equivalence and L2 vocabulary acquisition. International Journal of English Linguistics, 5(2), 1-7.Available at: https://doi.org/10.5539/ijel.v5n2p1.

Meara, P. (1996). The vocabulary knowledge framework. Vocabulary Acquisition Research Group Virtual Library. Retrieved from https://www.lognostics.co.uk/vlibrary/meara 1996c.pdf. [Accessed April 12, 2020].

Milton, J. (2009). Measuring second language vocabulary acquisition. Bristol: Multilingual Matters.

Milton., J., \& Fitzpatrick, T. (2014). Introduction: Deconstructing vocabulary knowledge. In J. Milton, E T. Fitzpatrick (Eds.), Dimensions of Vocabulary Knowledge. Hampshire: Palgrave Macmillan.

Nation, I. S. P. (2001). Learning vocabulary in another language. New York: Cambridge University Press.

Ordonez, C. L., Carlo, M. S., Snow, C. E., \& McLaughlin, B. (2002). Depth and breadth of vocabulary in two languages: Which vocabulary skills transfer? Journal of Educational Psychology, 94(4), 719-728.Available at: https://doi.org/10.1037/0022-0663.94.4.719.

Oxford, R. L. (1990). Language learning strategies: What every teacher should know. Boston: Heinle \& Heinle Publishers.

Pallant, J. (2011). SPSS survival manual: A step by step guide to data analysis using SPSS for Windows (4th ed.). Australia: Allen \& Unwin. 
Perfetti, C. A., \& Hart, L. (2002). The lexical quality hypothesis. In L. Verhoeven, C. Elbro, \& P. Reitsma (Eds.), Precursors of functional literacy (pp. 189-213). Amsterdam, The Netherlands: John Benjamins.

Proctor, C. P., August, D., Carlo, M., \& Snow, C. (2005). Native Spanish-speaking children reading in English: Toward a model of comprehension. Journal of Educational Psychology, 97(2), 246-256.

Read, J. (2000). Assessing vocabulary. Cambridge: Cambridge University Press.

Read, J. (1998). Validating a test to measure depth of vocabulary knowledge. In A. J. Kunnan (Ed.), Validation in Language Assessment: Selected papers from the 17th Language Testing Research Colloquium, Long Beach (pp. 41-60). Mahwah: Lawrence Erlbaum Associates.

Schmitt, N. (1997). Vocabulary learning strategies. In N. Schmitt, \& M. McCarthy (Eds.), Vocabulary Description, Acquisition, and Pedagogy (pp. 199-227). Cambridge: Cambridge University Press.

Schmitt, N. (2000). Vocabulary in language teaching. Cambridge: Cambridge University Press.

Sunderman, G., \& Kroll, J. F. (2006). First language activation during second language lexical processing: An investigation of lexical form, meaning, and grammatical class. Studies in Second Language Acquisition, 28(3), 387-422.Available at: https://doi.org/10.1017/s0272263106060177.

Teng, F. (2014). Assessing the depth and breadth of vocabulary knowledge with listening comprehension. PASAA: Journal of Language Teaching and Learning in Thailand, 48, 29-56.

Vermes, A. (2010). Translation in foreign language teaching: A brief overview of pros and cons. Eger Journal of English Studies, $10(1), 83-93$.

Wenden, A., \& Rubin, J. (1987). Learner strategies in language learning. U.K: Prentice Hall International.

Wesche, M., \& Paribakht, T. S. (1996). Assessing second language vocabulary knowledge: Depth versus breadth. Canadian Modern Language Review, 53(1), 13-40.Available at: 10.3138/cmlr.53.1.13.

Wolter, B. (2001). Comparing the L1 and L2 mental lexicon: A depth of individual word knowledge model. Studies in Second Language Acquisition, 23(1), 41-69.Available at: https://doi.org/10.1017/s0272263101001024.

Zheng, Y. (2011). Exploring Chinese EFL learners' vocabulary depth knowledge: The role of L1 influence. The Journal of Asia TEFL, 8(3), 191-219. 